\title{
BOF BLOWING PROCESS CHALLENGES FOR HIGH RATE OF IRON ORE PELLET ADDITION - PROCESS DEVELOPMENT AND RESULTS AT TKCSA *
}

\author{
Daniel Augusto Godinho de Carvalho ${ }^{1}$ \\ Herbert Castro ${ }^{2}$ \\ Leonardo Demuner ${ }^{3}$ \\ Marcos Viana ${ }^{4}$ \\ Pavel Wojnar ${ }^{5}$ \\ Roberto Formage ${ }^{6}$ \\ Tilo Schulz ${ }^{7}$ \\ Breno Totti Maia
}

\begin{abstract}
At thyssenkruppCSA, a positive heat balance at BOF process is faced, mainly because of low utilization of scrap and plant design. A singular logistic concept for hot metal transport between blast furnace and steel plant was established to optimize transportation and energy balance. Up to $80 \mathrm{~kg}$ of iron ore pellets/t steel is necessary for 340t BOF heat balance. In order to accomplish this challenge a stable blowing process, intensive operational development have been successfully executed: slopping rate reduction of $80 \%$ achieved without changing the blowing time. This paper describes steps and results of this development.
\end{abstract}

Keywords: BOF, LD converter, process, slopping, iron ore, addition, blowing process

\footnotetext{
Eng. Metalurgista MSc., Eng. Proc. BOF, Aciaria, thyssenkruppCSA, Rio de Janeiro, Brasil.

Eng. Controle Automação., Eng. Nível 2, Aciaria, thyssenkruppCSA, Rio de Janeiro, Brasil.

Eng., Produção, Gerente Geral, Aciaria, thyssenkruppCSA, Rio de Janeiro, Brasil.

Eng. Químico, Eng. Proc. Aciaria, Aciaria, thyssenkruppCSA, Rio de Janeiro, Brasil.

Eng. Automação., Eng. Automação, Primetals Czech Republic, Ostrava.

Engenheiro, Consultor Equip. Ambientais, Projetos, thyssenkruppCSA, Rio de Janeiro, Brasil.

Eng. Metalurgista PhD., Eng. Nível 2, Aciaria, thyssenkrupp SE, Duisburg, Alemanha.

Eng. Metalurgista Dr, Diretor Téc Comercial, Lumar Metals,Brasil.
} 


\section{INTRODUCTION}

thyssenkrupp started up in 2010 a 5 mtpy steelmaking complex from green-field at Santa Cruz, Rio de Janeiro, Brazil. A state of the art technology that allows production of high quality carbon steel grades with significant cost reduction as well challenging environmental limits had to be matched with a reasonable project costs. In many aspects, developments of a tailor-made concept with an appropriate solution were applied over the site (1).

The Steel Melt Shop at thyssenkruppCSA (tkCSA), average heat size of 340t steel, is composed of two Hot Metal Desulfurization plants (HMD), two BOF-TBM vessels, two Ladle Treatment Stirring stations (LTS), 1 Aluminium Heating Facility (AHF), 1 Vacuum Degassser Plant (RH) and 2 Continuous Casting Machines (CCM) with two strands of twelve segments each one. The second $\mathrm{RH}$ vessel is planned to start-up in April 2017.

Looking for the best adjustment between energy balance and project costs, the transportation of liquid Hot Metal (HM) from Blast Furnace to Steel Melt Shop (SMP) is made through the BOF HM charging ladle, which is handled by wheel steered ladle carrier. Furthermore, there is no HM reladle possibility and HMD process is made through lance injection in a multi injection technology (Fig.1).

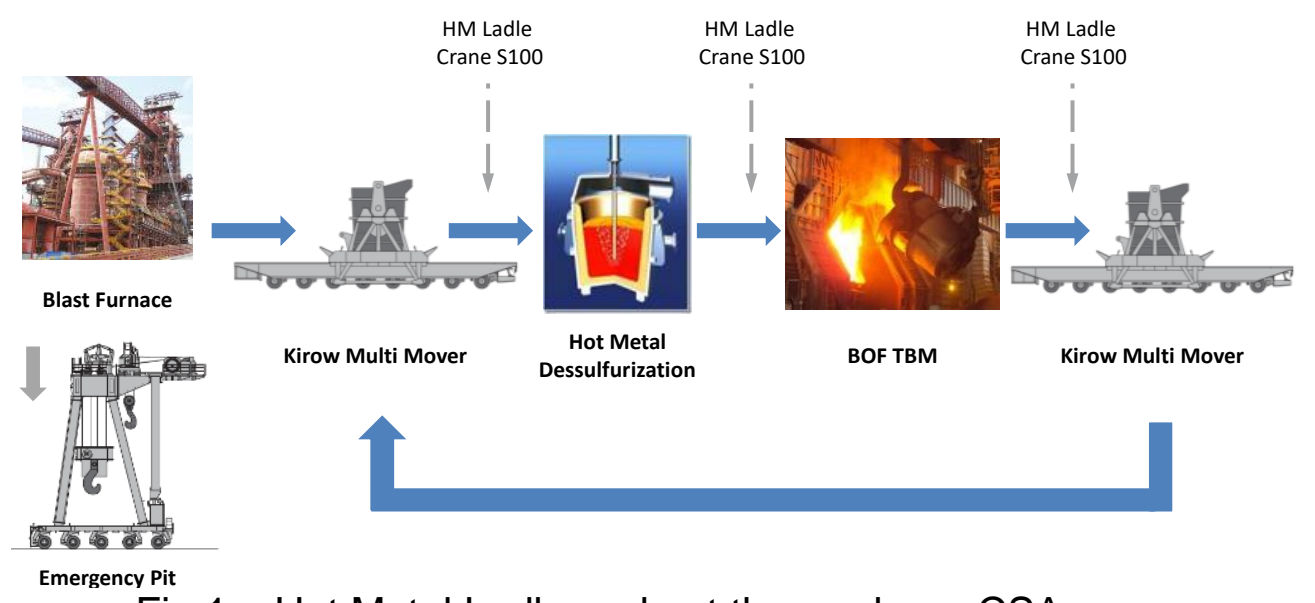

Fig.1 - Hot Metal Ladle cycle at thyssenkruppCSA.

As thyssenkruppCSA is a slab producer, therefore the internal the scrap generation is very low compared to full integrated plants, and as a strategic decision scrap purchase on market had to be minimized. It results in a high HM Ratio, on the other hand when it is necessary to increase production and/or high stock of beach iron is faced, high ratio of solid hot metal (pig and beach iron) charge will be faced.

The outcome of this plant layout and materials charging strategy is a fast HM ladle cycle, low HM energy loss between Blast Furnace tapping and BOF charging, the average $\mathrm{HM}$ temperature after $\mathrm{HMD}$ treatment is $1386^{\circ} \mathrm{C}$ (Figure 2 - left). In most heats there is a strong positive thermal balance and high ratio of cooling material addition, resulting in a challenging iron ore pellet addition in the right time and quantity. 

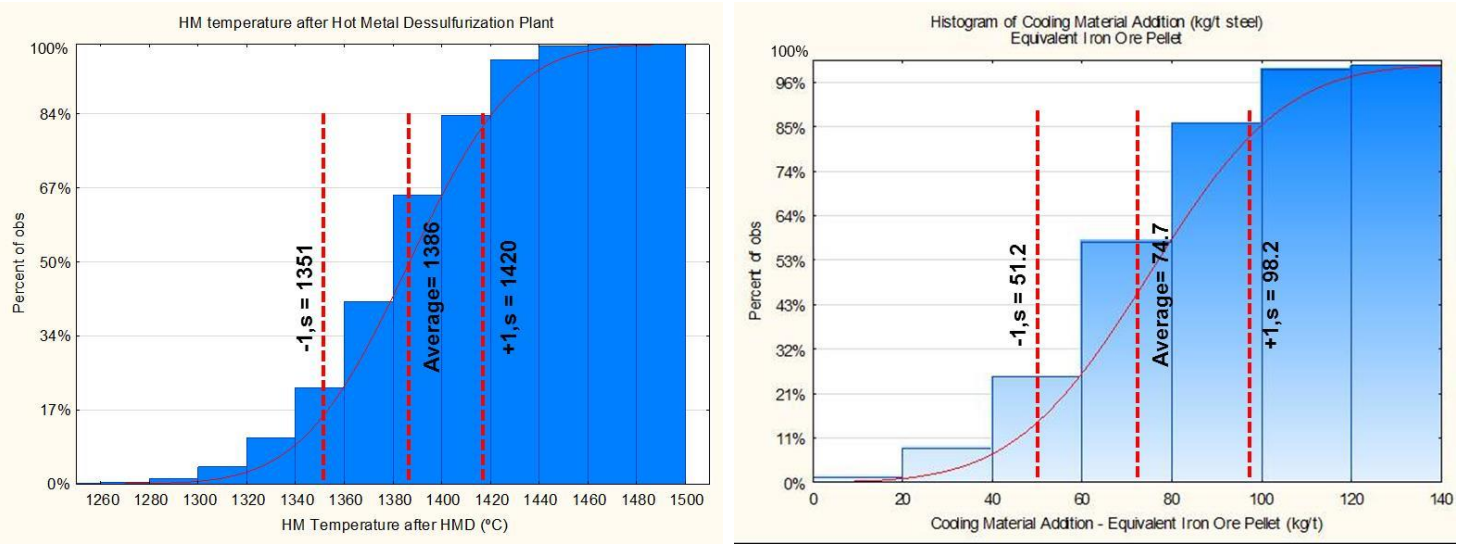

Fig. 2- Average HM temperature after HMD (left). Total cooling material additions (right).

The average addition for cooling materials on BOF is $74.7 \mathrm{~kg} / \mathrm{t}$ steel (Figure 2 right), this diagram is a plot of all cooling additions over the BOF process, and includes the pre-charged materials e.g. iron ore based materials. Such additions are made when extreme positive balance are faced. Even for heats with scrap on charge, a high iron ore pellets addition over the main blow is necessary (Fig.3).

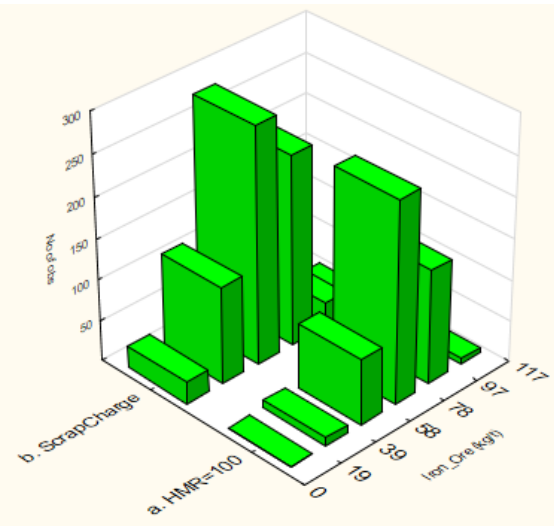

Fig. 3 - Iron ore pellet addition (kg/t) over the blow process (heats with or without scrap).

Since start-up phase in 2010 BOF slopping had been a problem for maintenance, operational and especially for environmental issues. This situation has forced the development of a new process to decrease the emissions due BOF slopping. In order to accomplish this challenge, a stable blowing process and intensive operational development have been successfully executed; the result was slopping rate reduction of $80 \%$ without changing the blowing time.

\section{Slopping literature}

There are several causes for slopping, such as pig iron quantity, flux quality, slag volume, previous BOF deslagging, quantity of exogeneous materials (slag basicity influence), blowing pattern and silicon content in hot metal [2]. The basic mechanism of BOF slopping is well known, nevertheless it is highly unpredictable. The dynamics of excessive slag foaming that results in slopping is a complex 
phenomenon depending on many variables such as slag condition (viscosity, surface tension, density), population of second phase particles within the liquid slag, gas bubbles size due to the decarburization process, rate of gas generation, BOF volume and geometry, cooling or heating effect of additions, blowing pattern, addition pattern, oxygen tip design, post combustion within or near the slag, gas pressure near BOF mouth, raw materials with high variable chemistry and others [3].

The negative effects of BOF slopping are well known; workers safety, dust emissions and damages to plant equipment such as furnace mouth, oxygen lance, off-gas and raw material addition system, ladle and slag pot transfer car, as well production losses due to blowing interruptions, iron yield reduction and other problems because of lower slag volume.

In regular BOF oxygen blowing process, the gases produced by decarburization reactions needs to pass through the slag layer and leave the vessel smoothly. The process design has to look for the best compromise between slag making and specific site practices in order to fulfil the aim steel quality and production needs.

When the process gas does not transit the slag layer smoothly; two kinds of slopping can happen. The first one, when the slag layer has low permeability and the gases pass through the slag layer slowly, a foamy slag with higher volume is produced, when the total volume of steel and slag melt is higher than the converter capacity, the slopping is faced. The second type of slopping, the most damaging one so called spitting, occurs when the gas cannot pass through the impermeable slag, the pressure between metal and slag layer increase as the gas volume increases, when the gas pressure is higher than the slag pressure, a considerable slopping like an explosion is faced [2].

\section{Slopping tracking at tkCSA}

At tkCSA, the slopping control while blowing is made by the BOF operator through the visual inspection, his decision is supported by level 1 off-gas measures (off gas flow, pressure, composition, etc..) as well by a close circuit television (CCTV) system, there is a camera keeping the focus on the mouth and the other below the BOF. For the first kind of slopping mentioned below, the CCTV is a good support for the operators. On the other hand, the second kind of slopping are unpredictable by camera inspection and are easier to be detected by level 1 measurement curves.

When the first slag overspill is faced, or abruptly change over the off-gas curves are detected, they can decide to push some of the four reaction buttons in order to mitigate the slopping effects. The anti-slopping reactions can vary from a simple bottom blowing flow change, skirt positioning to reduce the pressure, lance height change and other small and medium issues until strong process intervention such as stop all additions, oxygen lance flow reduction and in the last case interrupt the oxygen blow. The control of slopping event and severity at tkCSA is made through the tracking of this button, even if the operators push the button for preventive reasons.

\section{Slopping causes at tkCSA}


An internal study looking for the main influencing factor for slopping at tkCSA was conducted, variables and parameters related to scrap and hot metal charge, precharge addition, main blow additions, slag quantity and conditions were considered for a statistical analysis. This analysis has shown that iron ore pellet addition is the highest influencing parameter for slopping rate (Fig.4), the specific slag volume did not show a considerable influence for slopping (Fig.5), the reason, probably, is the good specific volume of the tkCSA TBM-vessel with $0,965 \mathrm{~m}^{3} / \mathrm{t}$ liquid steel.

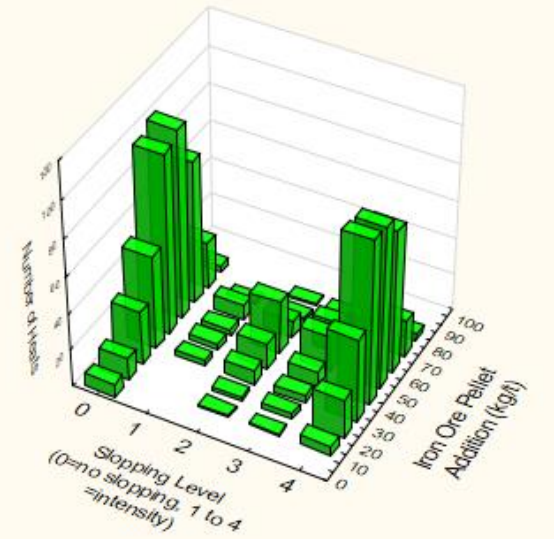

Fig. 4- Histograms of iron ore pellet addition according to slopping level event ( 0 = no slopping, $1=$ =very light, $2=$ light, $3=$ medium, $4=$ =strong) .

At thyssenkruppCSA, both BOF have a total inner volume of $328 \mathrm{~m}^{3}$, despite the nominal capacity of 330 t steel, the average tapping weight in last fiscal year was 340 t per heat.

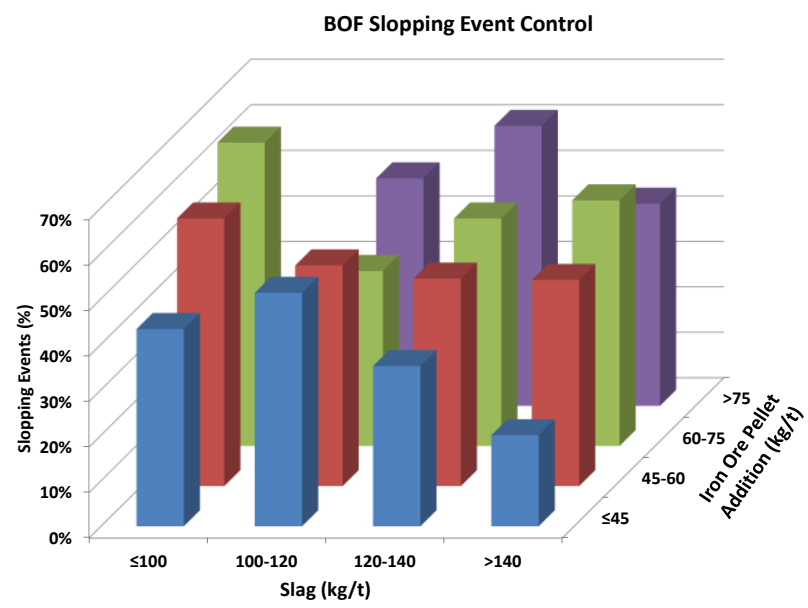

Fig.5 - Slopping frequency according to iron ore pellet addition and specific slag volume.

Another important variable found was the combination of high quantity of pig iron charged and high quantity of iron ore pellet added (Fig.6). The slopping probability for those heats with high pig iron charged and low iron ore pellets added was low. Nevertheless, a high slopping incidence was found for heats without pig iron charged and high iron ore pellets addition. 


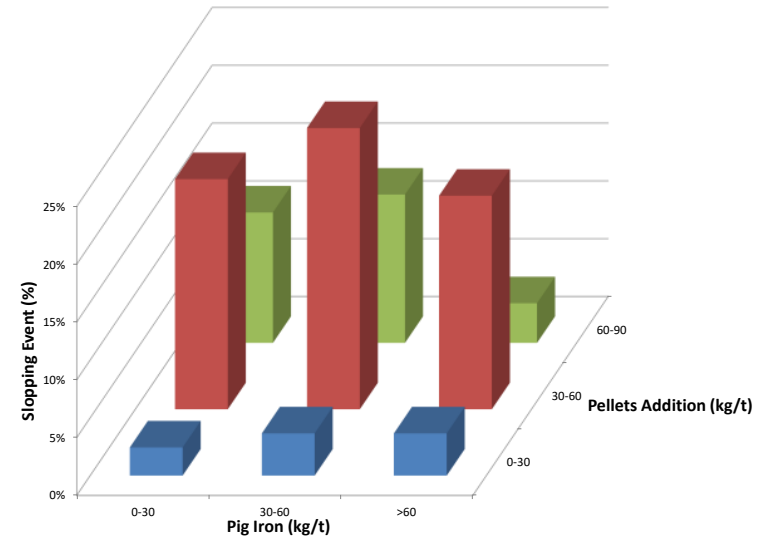

Fig. 6- Share of slopping event according to the level of pig iron charged and iron ore pellet addition.

Based on all statistical analysis indication, a definition to focus on iron ore pellet additions and all influencing factors connected to this issue was done. A real time observation was necessary, many heats were followed, the main tracked parameters was related to blowing process, additions set-points, off-gas system behavior and all BOF auxiliary equipment.

The main problematic occurrence of slopping at tkCSA was taking place around $35 \%$ of the blowing process, before the main decarburization process start. It was characterized by off-gas volume reduction followed by a fast off-gas volume and pressure increase, resulting in a strong and dangerous slopping.

Regarding to dedusting system and all auxiliary equipment, the maximum nominal oxygen flow capacity is $1,200 \mathrm{Nm}^{3} / \mathrm{min}$, it is the sum of oxygen blown through the oxygen lance and the oxygen available on iron ore pellet. Before the present work, all blowing patterns were designed looking for the upper flow limit condition, when iron ore pellet addition was necessary, the oxygen flow through the lance was reduced looking for the maximum oxygen flow input. The result was not like expected; the side effect of this oxygen flow oscillation through the lance was instabilities for the blowing process as well the IDF-fan control system, resulting in pressure oscillation, then a slopping due this "pumping effect".

A secondary cause of slopping was happening just after the interruption of iron ore pellet addition, this abruptly off-gas generation reduction was causing instabilities for the IDF-fan control system (Fig.7). The off-gas system could not equalize the internal pressure in time to avoid a considerable slopping event.

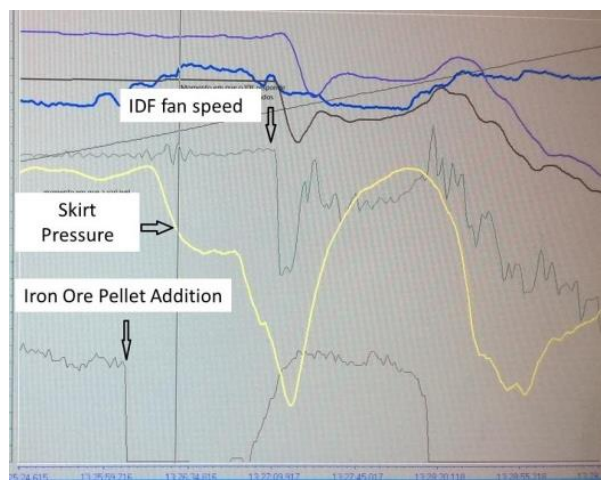


Fig. 7- Skirt pressure instabilities after abruptly interruption of iron ore pellet addition.

\section{Main actions to reduce slopping at tkCSA}

Most of the problems causing slopping were related to IDF fan loss of control, therefore all the process was designed looking for the maximum IDF control stability, have the oxygen blowing and iron ore addition process as smoothly as possible was the priority.

The IDF control is done depending on the process phase. Over the blowing phase, IDF fan speed is continuously controlled as a function of process gas generation inside the BOF vessel, as well other process parameters such as oxygen lance, instable oxides sources, etc. IDF fan speed is adjusted in such a way to keep the pressure measured on the skirt close to zero, just a little bit negative in order to avoid process gas post combustion.

A new blowing pattern was defined looking for the control stability, a constant oxygen flow of $90 \%$ comparing to former blowing pattern design was defined, this set point of oxygen flow is not changed even while the iron ore pellets is added. Later, a concept of oxygen lance stepless was created looking to optimize the slag forming phase. The steps were changed by a ramp down, resulting in a very smoothly lance movement and slag formation as well. All modification on the blowing pattern philosophy could reduce the process complexity. After this step, all efforts were concentrated over the iron ore addition itself.

The raw material handling system for each BOF contains of 10 daily silos for blowing additions. Three of them are originally assigned for iron ore material (capacity of $3 \times 100 \mathrm{~m}^{3}$ ). Material batches are charged in 6 weighing bunkers, where two can be used for iron ore addition. Material prepared in weighing bunker is than charged via vibrating feeder directly into converter. Vibrating feeders have adjustable feeding rate controlled by PLC. Material addition into converter is driven by a recipe table, where for every material batch amount and time trigger is defined. All recipe tables are defined by Level 2 model.

Exploring all material handling system possibilities, a new material addition pattern was defined aiming the reduction of sloping around $35 \%$ of the blowing process. An interruption of iron ore addition was done before the main decarburization period starts at around $25 \%$ of Oxygen blowing. In order to avoid the abruptly interruption of iron ore addition, a smoothly addition interruption was designed in a ramp down of 80 seconds; it could allow the IDF fan control follow the gas generation deviation.

Looking for a constant and defined end-point for iron ore pellet addition, below the recipe tables in control hierarchy defined by Level 2, a new distribution pattern based in flow control was developed. Maximum and minimum allowed feeding rate for iron ore can be defined as a range, where addition flow control function should work. This function is working like online calculation to evenly distribute ore addition over whole blowing process. Metallurgist can define what the latest point is when all 
ore should be fed into the vessel. The main function of this control is online flow rate recalculation to meet necessary targets. Desired flow rates are then used like setpoint for addition flow closed loop controller driving vibrating feeder.

\section{Results}

An intensive operational development was executed at tkCSA melt shop; challenging addition of iron ore pellets up to $80 \mathrm{~kg} / \mathrm{t}$ have been successfully done in a stable blowing process, the slopping rate could be reduced by $80 \%$ (Fig. 8) without changing the blowing time. The Steel Melt Plant dust emission could fall from 40 to 2 events a month, an important environmental issue controlled by Brazilian authorities.

The slopping event control was around 35\% before the present work, after the development it could be reduced to $7 \%$ in average (Fig. 9), all slopping severities are included in this control. The understanding of the process without the operator intervention is the aim of this control.
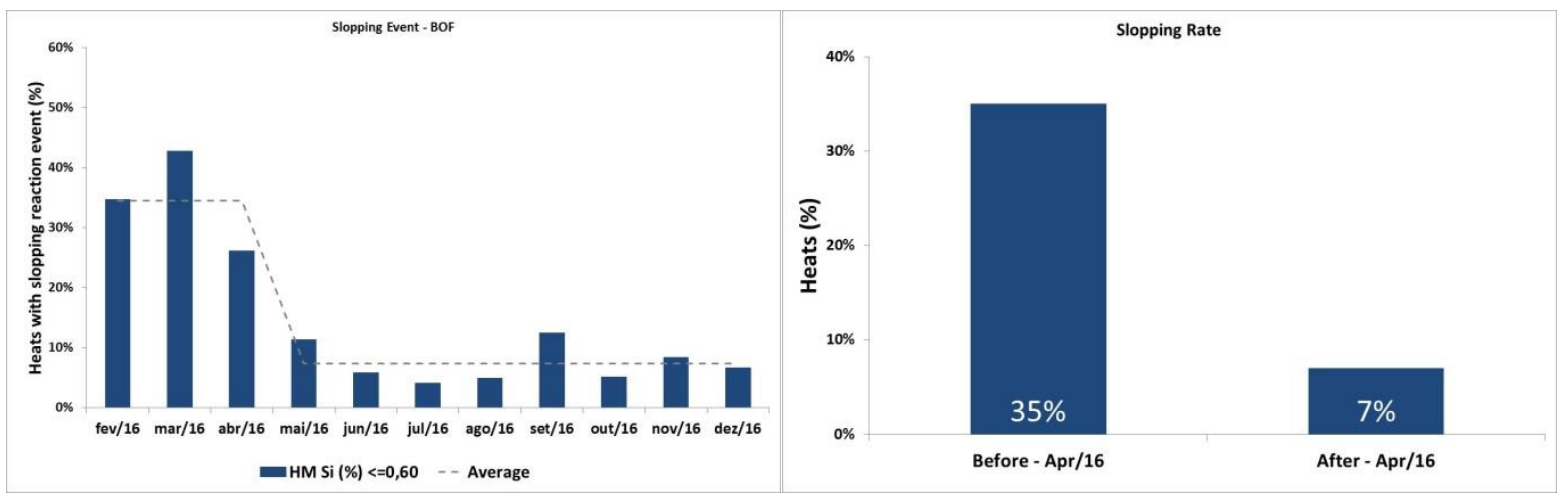

Fig. 8- Slopping event control.

The current figures of slopping at tkCSA show lower events and severity than before as well, the number available on steel melt plant dust emission control (Fig. 9) shows the same trend.

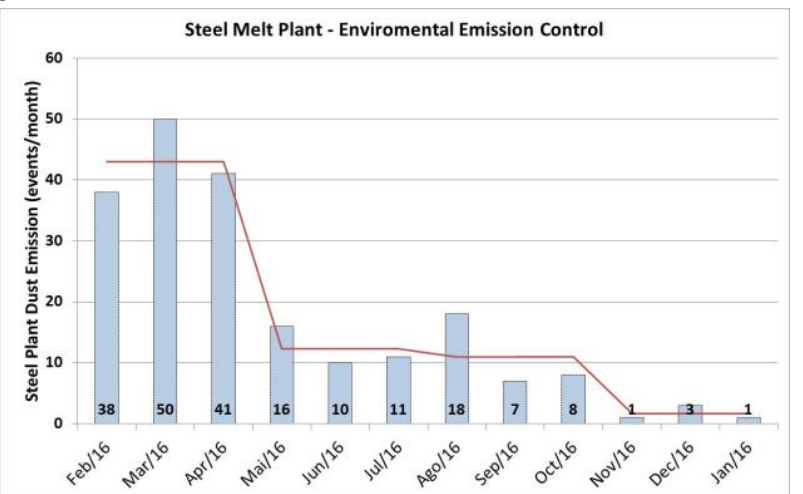

Fig. 9 - Steel Melt Plant - Dust emission control.

The global iron ore pellets addition over the main blowing process at tkCSA is $59.5 \mathrm{~kg} / \mathrm{t}$ in average (excluding pre charged additions), for heats charged only with 
liquid hot metal, this number rises to $70.6 \mathrm{~kg} / \mathrm{t}$ in average, many heats up to $80 \mathrm{~kg} / \mathrm{t}$ are necessary (Fig. 10).
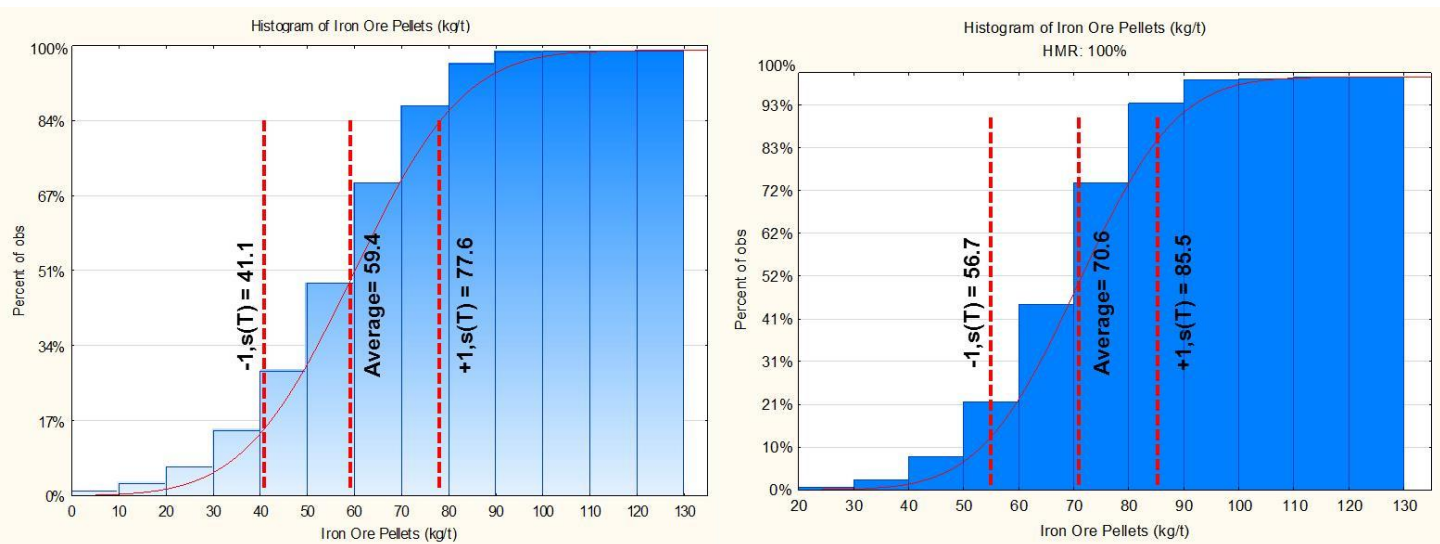

Fig. 10- Iron Ore addition over the blowing process (excl. pre charge)

Left: all heats (average of $59.4 \mathrm{~kg} / \mathrm{t}$ ). Right: HMR:100\% (average of $70.6 \mathrm{~kg} / \mathrm{t}$ ).

The average blowing time did not change considerable even with the oxygen flow reduction through the lance (Fig. 11). Actually, the global input of oxygen increase from $120 \%$ to $130 \%$ of the designed $\mathrm{O}_{2}$ Lance flow rate of tkCSA.

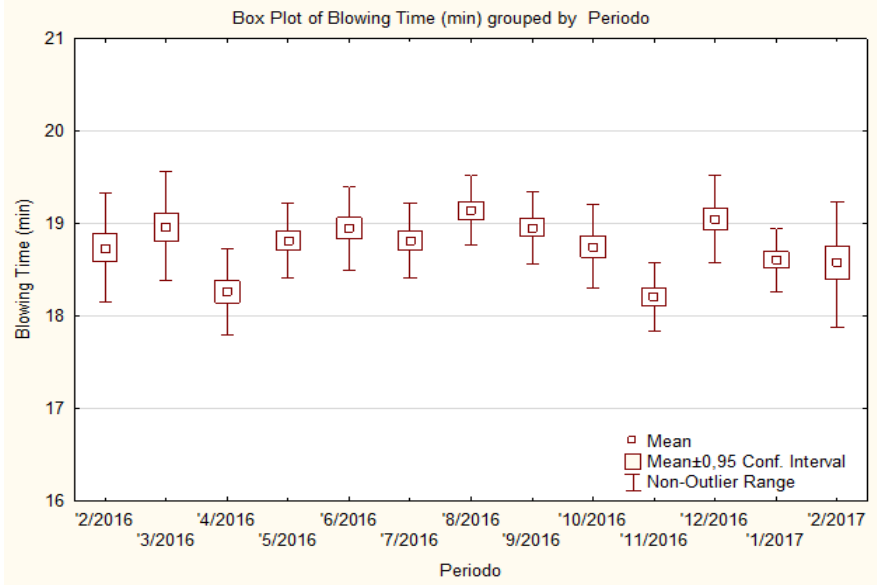

Fig. 11- BOF oxygen blowing time (min), monthly data.

\section{Literature Reference}

[1] Rasim, Dr. Wolfgang e Zentara, Dr. Norbert, An efficient and fit-for-purpose supply chain for 5 mio. tons of slabs per year over 3 continents. Dusseldorf : METEC Conference Proceedings, 2011.

[2] J. Pérez, R. Donayo, A.Gomez, W. Balante, Decrease of fume emissions in the Converter by new process for high-silicon and -phosphorus hot metal. AISTech Conference Proceedings, 2011, pp. 68-75.

[3] I. Todorovic, V. Scipolo, Improving BF-BOF Performance and Safety Using Tenova's Slop Detection System Technology. AISTech Conference Proceedings, 2012, pp. 937-946. 